\title{
What is Abstraction in Photography?
}

\section{ABSTRACT}

There is confusion about what counts as abstraction in photography: art theorists class very different kinds of photographs as abstract, and common philosophical views of photography, if true, should cause us to doubt their very possibility. I address two questions here: "What is Abstraction?" and "What is Abstraction in Photography?" To the answer the second, I briefly consider a third: "What is Photography?" so that the resulting account is not undermined by a poor theory of photography.

In answer to my target question, I outline a schematic (and non-exhaustive) typology of kinds of work generically typed as "abstract," in order to bring out some differences between them. I distinguish "proto," "faux," "constructed faux," "weak," "strong," "constructed" and "concrete" abstraction, although the differences between them are not always clear-cut, and there is room for debate about borderline cases. My goal is not to resolve all such cases, but to show that: i) there is a range of broadly identifiable kinds of abstraction in photography; ii) that images can be abstract in a variety of ways and for a variety of reasons; iii) when an image is not abstract, despite being widely typed as such, why it is not. 


\section{What is Abstraction in Photography?}

\section{The Problem}

There seems to be confusion about what counts as abstract photography: a cursory survey of the kinds of image classed as abstract photographs turns up a bewildering variety of cases, and it is not clear that all could be considered abstract according to a single definition. In philosophy the problem is compounded by the fact that there has been little work on abstraction by philosophers of depiction, and (almost) nothing on abstraction in photography. There is a literature on abstract photography among art theorists and critics, but it tends either to presuppose that since we already know what abstraction is, it is not necessary to define it — resulting in indiscriminate applications of the term —or to verge on the overly programmatic or prescriptive, with normative commitments being passed off as descriptive accounts. ${ }^{1}$ Given this lack of sustained attention to the term's intension, it is hardly surprising that the examples given often betray confusion as to its extension, at times appearing overly permissive and at other times overly restrictive.

To make a start on rectifying this I try to answer two questions here: "What is Abstraction?" and "What is Abstraction in Photography?" In order to the address the second, I also have to say something about a third: "What is Photography?" This is necessary if the account of abstract photography given is not to be undermined in

\footnotetext{
${ }^{1}$ See Lyle Rexer, The Edge of Vision: The Rise of Abstraction in Photography (New York:
} Aperture, 2013) and Gottfried Jäger, "Concrete Photography” in Jäger, Rolf H. Krauss, Beate Reese, Concrete Photography/Konkrete Fotografie (Bielefeld: Kerber, 2005), respectively. 
advance by a poor general theory of photography — a live possibility when common assumptions about the nature of photography can still give rise (at least in philosophy) to the impression that there is something inherently problematic about the very idea of abstraction in photography, the documentary art par excellence. I argue that this stems from unreflectively internalizing a tendentious folk theory of photography—a theory that is benign so long as it is correctly perceived as local, but prejudicial as soon as it is mistaken for global. ${ }^{2}$

By way of an answer to my target question, "What is Abstraction in Photography?" I consider the most notable rival account, before outlining a schematic and non-exhaustive typology of various kinds of work generically typed as "abstract," in order to bring out some basic distinctions between them. To this end I distinguish "proto," "faux," "constructed faux," "weak," "strong," "constructed" and "concrete" abstraction, although the differences between them are not always clear-cut, and there is scope for debate about borderline cases. My goal is not to resolve all such cases here, but to show that i) there is a range of broadly identifiable kinds of abstraction in photography, and that these can be distinguished, at least in most instances, and ii) when an image is not in fact abstract, despite being widely regarded as such, why it is not. The resulting typology is descriptive: it is meant to draw attention to some ways in which images generically typed as abstract may differ, not to imply any normative judgements as to their respective merits, or lack thereof, as art.

\footnotetext{
${ }^{2}$ See AUTHOR REF 1
} 


\section{What is Abstraction?}

In art theory, "abstract" tends to be used as a contrast category to "figurative," and means essentially non-depictive. A picture is abstract when one can no longer see any recognizably three-dimensional objects in it. ${ }^{3}$ Pictures that are abstract in this sense may still trigger a perception of depth (as when one shape or colour seems to float in front of, or recede behind, or be seen thorough, another) but cannot prompt us to see three-dimensional objects in their surfaces, on pain on collapsing back into depiction. Precisely when a picture is abstract in this sense need not always be clear-cut: some figure-ground relations seem to hover indeterminately between the two.

Clement Greenberg was the leading theorist of this way of understanding abstraction in art theory. In Greenberg's terms, an abstract picture permits "optical" depth but not "trompe-1'oeil" or "modeling in the round." On his historical account, which I shall largely bracket here, abstraction in painting is the outcome of a process of gradual "silting up" of pictorial space from the latter third of the $19^{\text {th }}$ Century onward. What Greenberg calls "optical” illusion survives this development; the depiction of objects in three-dimensional space does not. ${ }^{4}$ But note that it not the depiction of recognizable objects per se, so much as depiction of the kind of space that such objects inhabit, that precludes abstraction for Greenberg is. Recognition of

\footnotetext{
${ }^{3}$ For the purposes of this paper, I assume an experiential, viewer-focused approach to abstraction - any picture is abstract that it is correctly experienced as such by a viewerrather than, say, an intentionalist, artist-centred theory of abstraction — any picture is abstract that the artist intends as such.

${ }^{4}$ Greenberg, "Modernist Painting," The Collected Essays and Criticism, Vol. 4, ed. John O’Brian (Chicago: Chicago University Press, 1993), p. 90.
} 
everyday three-dimensional objects is sufficient to cue perception of such space, and is as such incompatible with abstraction proper. $^{5}$

Major philosophers of depiction, by contrast, have had surprisingly little to say about abstraction, despite its centrality to the art in the $20^{\text {th }}$ Century. Setting aside his psychoanalytically inspired interpretation of Willem de Kooning, Richard Wollheim includes a single page on the idea of abstraction in Painting as an Art. And Kendall Walton devotes just three pages to the extension of his account of imagined seeing to abstract pictures in Mimesis as Make Believe. Given the history of $20^{\text {th }}$ Century art this is remarkable: yet, between them, Wollheim and Walton remain responsible for many of the current debates in the philosophy of depiction.

On Wollheim's mature theory, perception of pictures is "two fold:" it involves simultaneous awareness of a picture's "configurational" and "recognitional" aspects. ${ }^{6}$ When one appreciates a picture aesthetically one is simultaneously aware of its design properties — the colours, shapes, forms and marks arrayed across its surface — and what may be seen in the surface so configured. ${ }^{7}$ On Wollheim's theory these are "two folds" of a single, dual-aspect experience, not simultaneous awareness of two distinct phenomena. $^{8}$

Given that nothing recognizable can be made out in the surface of an abstract picture, one might expect two-foldness to be ruled out in principle on this account, leaving one's experience of the configurational aspects of the marked surface as the

\footnotetext{
${ }^{5}$ Ibid., p. 87.

${ }^{6}$ Richard Wollheim, Painting as an Art (London: Thames \& Hudson, 1987) p. 21, p. 73.

${ }^{7}$ Ibid., p. 75. See also Wollheim, "Seeing as, Seeing-in and Pictorial Representation," in Art and its Objects $2^{\text {nd }}$ Edition (Cambridge: Cambridge University Press, 1980), pp. 212-214.

${ }^{8}$ Wollheim, Painting as an Art, pp. 46-7.
} 
sole focus of appreciative attention. But this would be too quick: both figurative and abstract paintings are two-fold, and hence representational, for Wollheim. Not only do both have marked surfaces, but something can be seen in the marked surfaces of both. Where they differ is with respect to what can be seen in them. Wollheim distinguishes between them on the basis of the kind of concepts one would need to pick this out: in the former case, we might speak of seeing a dancer, street scene or vase of flowers (identifications that make use of "figurative" concepts); in the latter, of seeing an irregular solid, or overlapping rectangles in space (identifications that make use of "abstract" concepts). Appealing to the very distinction at issue in this way renders Wollheim's own explanation more circular than informative, but it is not my goal to press this criticism here. Suffice to say here that "abstract" and "figurative," however these might be non-circularly redefined, is a distinction within representational art, not a distinction between representational and non-representational art. We remain aware of both the marked surface and what may be seen in that surface, in all but the limit cases of the uninflected monochrome and (notoriously) the trompe-l'oeil still life. ${ }^{9}$

Walton concurs with this: because abstract painting continues to mandate "imagined seeing," it continues to count as a representational art. Simply in virtue of prescribing imaginings about figure-ground relations, almost all non-figurative paintings continue to function as "props" in games of make-believe. Take the perception of one coloured shape as lying in front of, and thereby occluding, another solid shape in Malevich's Suprematist Painting (1915), despite the fact that its surface is flat and made up of shapes notched into one another, rather than laying one in front

\footnotetext{
${ }^{9}$ Richard Wollheim, Painting as an Art, p. 62.
} 
of another in three dimensional space. ${ }^{10}$ Just as the distinction between figurative and abstract should not be mistaken for that between representational and nonrepresentational in Wollheim, so it should not be mistaken for that between supporting or not supporting imagined seeing in Walton. Rather, as it is a distinction between the kinds of entity that may be seen in the surfaces of different pictures for Wollheim, so it is a distinction between the kinds of entity we are mandated to imagine seeing when looking at different pictures for Walton. In the case of abstract pictures, we are prescribed to imagine various things about features of the paintings themselves, such as the spatial relations that obtain between the coloured rectangles in the Malevich. In the case of figurative pictures, we are prescribed to imagine various things about what those picture depict, hence about something other than picture, even if these imaginings are occasioned by looking at the picture itself.

Wollheim and Walton discuss abstraction in passing; Michael Newall is the first philosopher of depiction in the analytic tradition to give it sustained attention. Newall characterizes the view that abstract pictures may facilitate an experience of seeing relations of depth, overlap and transparency that are not literally present (but not everyday objects) as "non-veridical seeing without recognition of volumetric form." Perception of volumetric form, so construed, would mark the difference, in Wollheim's terms, between "abstract" and "figurative" seeing-in. ${ }^{11}$

So far so consistent with the accounts already surveyed. What distinguishes Newall's approach is that it is grounded in the premises of vision science. Because

\footnotetext{
${ }^{10}$ Kendall Walton, Mimesis as Make Believe; On the Foundations of the Representational Arts (Cambridge: Harvard University Press, 1990), pp. 55-7.

${ }^{11}$ Michael Newall, "Abstraction," in What is a Picture? Depiction, Realism and Abstraction (Basingstoke: Palgrave Macmillan, 2011), p. 173.
} 
human vision evolved for recognitional purposes - to detect objects, properties and kinds in our immediate environment - it is well equipped to detect features (such as edges, colour, texture) that subtend such recognition. ${ }^{12}$ Given this starting point, Newall's account of abstraction must meet two conditions: i) it should allow that abstract images can depict properties and kinds, but not objects, on pain of collapsing back into depiction; and ii) only properties and kinds of a certain sort. The kinds comprising two dimensional shapes, lines and marks depicted in shallow space as parallel or near parallel to picture plane, and the properties being those that such kinds can take on when depicted in a two dimensional surface, such being seen, nonveridically as overlapping, transparent, interpenetrating, and so on. So understood, abstract painting, despite frustrating the volumetric form recognition to which vision is attuned, continues to engage our recognitional abilities nonetheless: it occasions non-veridical seeing of a range of properties and kinds, but excludes recognition of volumetric form. ${ }^{13}$

Terminological differences aside, Greenberg, Wollheim, Newall and Walton are committed to essentially the same conception of abstraction in painting. Abstract painting is two-fold in a distinctive sense; it permits limited perception of depth and spatial relations between forms, planes and lines - in Walton's terms, it serves as a prop in a game of make believe spectators are mandated to play with the picture- but rules out perception of three-dimensional objects on pain of collapsing back into figuration. On the shared account of pictorial abstraction that emerges, a picture is abstract if and only if it is "two-fold" (Wollheim) in a distinctive sense: (i) it permits "non-veridical" (Newall) perception of depth and spatial relations between lines,

\footnotetext{
${ }^{12}$ Ibid, p.177ff.

${ }^{13}$ Ibid, p.178.
} 
forms and plains in a shallow space (or what Greenberg would call "optical illusion" and Walton "imagined seeing"); but (ii) rules out perception of three dimensional objects in space (or what Newall would call "volumetric form") on pain of collapsing back into depiction.

\section{What is Photography?}

So much for pictorial abstraction in general; what about abstraction in photography? The only philosopher to have seriously engaged with this question to date is Lambert Wiesing, but I shall hold off considering his account until I have tabled my preferred theory of photography. Before we can ask about abstraction in photography, we must be explicit about our conception of the latter if we want to head off assumptions that can make the very idea of abstract photography seem problematic.

Until recently, philosophical consensus conceived photography as an automatic image-rendering process, in which a mechanical apparatus (the camera) generates images that depend causally and counterfactually on what they depict. What I call "Orthodoxy" presents a powerful and intuitively appealing, if rather simplistic, explanation of photography's oft-noted epistemic advantage over other, hand-made ("manugraphic") forms of depiction: it is because photographic imaging mechanizes out the fallibility of human beings as recording agents that we accord its products the evidential weight that we do. But the theory has weaknesses as well as strengths, and the two are internally related: if bracketing the photographer's subjectivity explains photography's epistemic advantage, it also implies its aesthetic disadvantage. For it is not implausible to suppose that we look to art for just those traces of subjectivity, as revealed by what a given artist chooses to thematize or suppress, and how she goes 
about doing so, that automatic image-rendering is meant to bracket. It is the particular artist's vision of the world, and not the world simpliciter, that draws us to the work of individual artists. This holds for photography as much as it does for any other art. Yet this is precisely what automatic imaging is supposed to bypass.

This trade off between epistemic and aesthetic capacity has motivated a new generation of philosophers to develop an alternative theory. What makes the new theory new is, above all, how it marks the difference between photographic and nonphotographic forms of imaging. This no longer turns on a contrast between machine and handmade images: rather than being differentiated by the mechanical nature of its apparatus, the automaticity of its process, or the natural counterfactual dependence of the resulting images on their sources, photographic imaging is henceforth identified by whether or not it implicates a "photographic event" in its causal history, that is, an event of recording information from a passing state of a light image formed in real time on a light sensitive surface. This can, but need not be, the camera's film plane or censor: it might equally be a piece of photographic paper or film exposed directly to a light source. What matters, as the term "photography" implies, is the role of light in generating the image.

This, one might think, is hardly news. In fact, the new theory is not so much new as reminder of what we already know. It can be traced back to Patrick Maynard's characterisation of photography as a "branching family of technologies, with different uses, whose common stem is simply the physical marking of surfaces through the agency of light and other radiations." 14 This description is notable chiefly for the many things it does not say: there is no mention of automatic recording, mechanical

\footnotetext{
${ }^{14}$ Patrick Maynard, The Engine of Visualization: Thinking through Photography (Ithica: Cornell University Press, 1997), p. 3.
} 
apparatus, machine-made images, belief-independence or natural counterfactual dependency - the backbone of all orthodox accounts. Rather than focusing on what is special about a photograph's relation to what it is of, Maynard's account directs our attention to what is distinctive about photography as a process for making images. This is significant because any account that begins by trying to isolate what is special about a photograph's relation to its source builds in, without argument, a commitment to reference that the theory then has to make sense of. On Maynard's account, by contrast, what is distinctive about photography is not some special relation between a photograph and what it is of, but the nature of the photographic process-specifically, the role of light in the production of the image. Because he does not assume from the outset that all photographs have referents, only some of the resulting images need be pictures, and only some of those pictures need be of anything. As a result, his account builds in no commitments to realism, resemblance or even reference-no requirement that a photograph have an object, something that it depicts or causally refers back to, in order to count as such. The relevance of such an account to thinking about abstract photography will be obvious.

So much for the historical roots of new theory: the emergence of new theory proper can be traced to Dawn Wilson's use of this approach to target the assumption, common to folk theory and orthodoxy alike, that photographs come into existence at the moment of exposure. ${ }^{15}$ This turns out to be false in both the analogue and digital case. In the analogue case, exposing the film to light creates a latent image, but the film needs to be processed before that image becomes visible and, if the film is negative or colour reversal, it also needs to be printed before it can be appreciated. In

\footnotetext{
${ }^{15}$ Dawn M. Wilson (née Phillips), "Responding to Scruton's Scepticism," British Journal of Aesthetics 49:4 (2009), pp. 335-340.
} 
the digital case, exposing the camera's CCD sensor to light causes the capacitors that make up its surface to transmit electrical charges, but the charged or uncharged state of those capacitors not only has to be recorded, the resulting code has to be output through several stages of digital processing before it can generate a visible image. This process, though too quick to be humanly detected, nonetheless consists of stages that can be distinguished, both functionally and conceptually: output the same code through a different set of algorithms and it need not even generate an image file. Processed differently, it might be output as sound, and this shows there is a distinction to be drawn between the information stored and the algorithms required to output that information in visual form.

In neither the analogue nor digital case, then, are photographs produced simply by exposing a light sensitive surface. More is required, precisely what more varying between theorists. These differences need not detain us here; it is what they have in common that is important. ${ }^{16}$ Whereas for orthodox theorists the recording of information from an image focused onto a light sensitive surface is sufficient, for new theorists it is merely necessary. And this means that any further stages of image processing without which there could be no visual image to appreciate must be part of photography proper. If there cannot be a visually appreciable image without such stages, they can hardly be dismissed as incidental. Such stages can, but need not, be automated; and in many cases, both historical and contemporary, they have not been. This includes everything from minor darkroom adjustments to compensate for poor contrast, exposure and the like through to elaborate combination printing in analogue photography and their digital equivalents. Such examples cannot be ruled out simply because they conflict with photography's presumed mind-independence or natural

\footnotetext{
${ }^{16}$ On these differences, see AUTHOR REF 1 and AUTHOR REF 2.
} 
counterfactual dependence on its sources. For that would be to assume the truth of orthodox premises, when it is precisely the truth of such premises that is in question. ${ }^{17}$

What differentiates photography from painting, on the new theory, is not mind-independence, automatism, mechanism, or natural counterfactual dependence, but the fact that some images are made using photographic technologies and others are not. So the real question is: what makes a technology photographic? What makes a process photographic is that it implicates a photographic event in its causal history. Because traditional darkroom techniques in analogue photography, such as dodging and burning, double-exposure and use of multiple enlargers all implicate such events, as do the manipulation of hue, contrast, saturation and gradient mapping in digital photography, all still count as photographic according to new theory-irrespective of whether they preserve belief-independence. On Dominic McIver Lopes's formulation:

[A]n item is a photograph if and only if it is an image that is a product of a photographic process, where a photographic process includes (1) a photographic event as well as (2) processes for the production of images. ${ }^{18}$

Lopes's definition consists of two independent clauses and it is their independence that is crucial: because the first secures the distinction with non-photographic images, the second no longer need discharge this burden. This frees up the processes used to create photographic images to be anything photographers want them to be-so long as they continue to implicate an event of photographic recording. Photography no

\footnotetext{
${ }^{17}$ See Paloma Atencia-Linares, "Fiction, Nonfiction and Deceptive Pictorial Representation," Journal of Aesthetics and Art Criticism 70:1 (Winter 2012), pp. 22-24.

${ }^{18}$ Dominic McIver Lopes, “Jetz sind wir alle Künstler," in Julian Nida-Rümelin and Jakob Steinbrenner (eds.) Fotographie: zwischen Inszenierung und Dokumentation (Ostfinden: Hatje Cantz Verlag, 2012), p. 106ff.
} 
longer need be belief-independent, nor requires a contrast class of belief-dependent, intentionally mediated images. From an orthodox perspective, this will seem far too permissive, and the obvious solution would be to build back in something like natural counterfactual dependency:

$[\mathrm{A}] \mathrm{n}$ item is a photograph if and only if it is an image that is a product of (1) a photographic event and (2) processes for the production of images that (3) ensure belief-independent feature-tracking.

Less resolute, second-generation orthodox theorists, and perhaps also less permissive new theorists than Lopes himself, may want to quality this:

[A]n item is a photograph if and only if it is an image that is a product of (1) a photographic event and (2) processes for the production of images that $\left(3^{*}\right)$ generally ensure belief-independent feature-tracking. ${ }^{19}$

Lopes might even agree. But from his perspective, the question will be: what forces the concession? Whether $(3)$ or $\left(3^{*}\right)$ obtain will depend on the social institutions that a given form of photography serves, not any general features of photography. Medical, scientific, diagnostic, forensic and legal practices are all "knowledge-oriented," and this imposes additional constraints on the legitimate uses of photography within these domains: notably, that they not misrepresent the relevant facts and thereby encourage false beliefs about the domain in question. But such restrictions are not constitutive

\footnotetext{
${ }^{19}$ By "less resolute" orthodox theorists I have in mind Catherine Abell and Robert Hopkins. By "less permissive" new theorists Paloma Atencia-Linares and (perhaps) Dawn Wilson. See AUTHOR REF 1.
} 
features of photography per se. If they were they could not be broken, yet they often are. Orthodoxy conflates what is true of a highly visible, and socially very important, subset of photographic practices with what is true of photography per se. This is why it has difficulty accommodating photographic art in general, and abstract photography in particular. For new theory, by contrast, neither presents a problem: a photograph is a visual image, the causal history of which necessary implicates an event of recording information from a light image. Whatever further restrictions need be invoked to explain a given stretch of photography will be institutional in nature, not features of photography in general.

\section{What is Abstraction in Photography?}

Pause to consider what we have seen so far. "Abstraction" is not the absence of depiction, but a restricted form of the same, in which one has the experience of seeing spatial relations - notably relations of depth between planes, colours or lines - in a flat surface, but not volumetric forms or everyday objects. "Photography" is a wide array of practices, subtending diverse institutions, for creating, storing, and displaying "photographs," where the latter are understood as images that necessarily implicate an event of recording information from a light image in their causal history, but require further imaging processes — which may, but need not, be photographic — to make that information available in a form that can be visually appreciated. Given a sufficiently determinate notion of abstraction, and a sufficiently broad conception of photography, such as these, there is no problem in principle with the idea of abstract photography. 
Lambert Wiesing concurs in "What Could 'Abstract Photography' Be?," the most serious engagement with abstract photography by a philosopher to date. Wiesing distinguishes the empirical question of what abstract photography is and has been, from the conceptual question of what the idea of abstract photography permits, noting that since what is actual need not exhaust what is possible, one cannot get to the latter simply by enumerating the former. This is why surveying the field of abstract photography, as is done in exhibition catalogues and the like, cannot yield a philosophically satisfying answer. For this reason Wiesing focuses solely on what he takes to be the properly philosophical, conceptual question. But it bears noting that both approaches to the question — the empirical and the philosophical—presuppose some conception of both abstraction and photography, the former to so much as to identify the entities that fall within the domain to be surveyed, the latter to say what the concept at stake, construed in such and such a way, permits in principle.

In terms of the alternatives presented here, it is not clear where Wiesing stands: some of what he says suggests new theory, some orthodoxy, and some is ambiguous between the two. On what he calls a "wide" definition of photography, for example, "photographically produced products are always traces that can be explained physically and chemically. Photographs are what they are on the basis of relations of cause and effect: they are the permanently visible result of manipulated radiation."20 This is wide by comparison to a narrower definition of photography as the "technical production of figurative images [that resemble their sources] by means of optical

${ }^{20}$ Lambert Wiesing, "What Could 'Abstract Photography' Be? in Wiesing, Artificial Presence: Philosophical Studies in Image Theory, trans. Nils F. Schott (Stanford: Stanford University Press, 2010), p. 62. 
transformation and conservation of traces of light." ${ }^{21}$ While the narrow definition clearly implicates orthodoxy, a resolute new theorist will likely find Wiesing's wide definition still too narrow. For photography cannot be exhaustively explained in nonagential physical and chemical terms alone: this is what orthodoxy maintains, and it does not yet build in enough to account for an image that can be visually appreciated. Reference to "manipulated radiation" might build in what is required, but it depends on what "manipulation" permits, and Wiesing declines to say.

Wiesing has much less to say about the idea of abstraction itself, beyond distinguishing a wide philosophical notion of abstraction, understood as the absence of implication for other concepts, from a narrow art theoretical notion, construed as a lack of figuration: "a picture is abstract, in this [latter] sense, when no visible object can be discerned in it." 22 This is consistent, so far as it goes, with what I have said here; but unpacking what might mean for a photograph, given its means of generation, to preclude perception of "visible objects" turns out to be harder than one might think. The taxonomy that follows shows that difficulties arise for the more obvious answers. Wiesing himself defers to the champion and practitioner of "Concrete Photography" Gottfried Jäger on such questions, by presenting photographic abstraction, in broadly modernist terms, as a reduction to essence. ${ }^{23}$ Thus, in terms of process, "abstraction" can mean abstracting from camera and lens in favour of "preserv[ing] as visible traces the action of light on substances sensitive to light." ${ }^{24}$ Further abstraction may involve reducing out the negative in Photograms, the object that occludes the flow of light in Luminograms, right through to the borderline case of seeming (but only seeming) to

\footnotetext{
${ }^{21}$ Ibid.

${ }^{22}$ Ibid., p. 63

${ }^{23}$ Ibid., pp. 71-9.

${ }^{24}$ Ibid., p. 64.
} 
dispense with light itself — in favour of directly manipulating chemicals on a sensitive surface. In fact, as Wiesing points out, fixing light remains central to Chemigrams and, if it did not, they would not count as photographs. This is a point on which Wiesing, Jäger and new theorists from Maynard on can agree.

But his broader theory remains too dependent on Jäger's practice and selfunderstanding to capture much that is in the domain. To show this, I now turn to the breadth of photographic abstraction, which comes in a wide variety of shades and strengths. Even philosophers would do well to pay attention to empirical matters-if they want their definitions to be adequate to the domains under discussion. Faced with such diversity, Wiesing could deny that much of it is abstraction, thereby vitiating one constraint on empirically informed and critically sensitive philosophizing, or broaden his own account's scope, albeit at the expense of its dependence on Jäger's.

\section{Proto-Abstraction}

What I call "proto-abstraction" can, as the name implies, be considered a way stage on the road to abstraction proper. It typically depicts recognizable objects, but framed or lit in such a way as to draw attention, when photographed, to the resulting image's design properties. This is achieved by a combination of bold and simplified gestalts, unusual points of view, strong lighting, close ups and other crops that direct attention to visual patterning in the image. Given, however, that this still involves recognition of everyday objects, it clearly cannot count as abstract on the forgoing account. It is formalist, rather than abstract proper. 
Proto-abstraction was common among photographers attracted to abstraction in the other arts, but unable or unwilling to forgo the depiction of recognizable objects altogether for the sake of full blown photographic abstraction. Examples include Paul Strand's Abstraction, Twin Lakes Connecticut (1916) and some of his early cityscapes, and Edward Weston's 1936 series of Sand Dunes Oceano, all of which depend on an interplay of framing and strong, natural light. Other examples depend on dramatically “tipped up," points of view (Strand's View from the Viaduct, New York [1916], László Moholy Nagy's Berlin Radio Tower [1928] or André Kertész's images of Washington Square in the snow [1954]).

The fact that photography proved slower than many other arts to embrace abstraction in its full-blown form may not be surprising, given how widespread the idea that photography is at bottom an art of documenting the world was and still is. Strand himself celebrated photography's supposed "absolute, unqualified objectivity," despite the fact that both his own work, and the terms in which he celebrated that of others, shows how misleading a characterisation this is for the kind of distinctive personal vision he had in mind. ${ }^{25}$ Meanwhile leading theorists of modernism, both within and without photography, took an orthodox conception of photography more or less for granted—despite modernism's inbuilt telos towards abstraction. ${ }^{26}$

\footnotetext{
${ }^{25}$ Paul Strand, "Photography," in Alan Trachtenberg (ed.) Classic Essays on Photography (New Haven, CT: Leete's Island Books, 1980), pp. 141-142. For a discussion, see AUTHOR REF 1.

${ }^{26}$ Clement Greenberg, "The Camera's Glass Eye: Review of an Exhibition by Edward Weston" in The Collected Essays and Criticism, Vol. 2., ed. John O'Brian (Chicago: University of Chicago Press, 1986); Siegfried Kracauer "Photography," in Theory of Film: The Redemption of Reality (Oxford: Oxford University Press, 1960), and John Szarkowski, preface to The Photographer's Eye (New York: MOMA, 2007).
} 


\section{Faux-abstraction}

Faux-abstraction is a close cousin of proto-abstraction and the two can be hard to distinguish in some cases. It consists chiefly of various strategies of estrangement and defamiliarization that isolate objects from their everyday environments, or frame them in such a way as to delay or frustrate recognition of what one is looking at. What is especially interesting about faux-abstraction in this context is that it depends, for its dramatic effect, on leveraging the orthodox assumptions of viewers. Photographs in this vein occasion such delight largely because it is widely assumed that photographs necessarily show us how some corner of the world looked at some moment of time. Set aside whether such assumptions are true; were they not in play, these works could not carry the charge that they do.

Jaromir Funke's Abstract Fotos (1927-9) of complicated shadow patterns are one obvious example, Minor White's land and seascapes employing points of view (such as Bullet Holes (Middle Canyon, Capitol Reef, Utah [1961] and Stony Brook State Park, New York [1960]) that make it hard to be sure what one is looking atthough it is clear that one is looking at something - another. It is hard to overstate how widespread faux-abstract and related tendencies are in photography. The act of cutting away the rest of the world with the image edge, fundamental to much (if not all) photography, often works to estrange and abstract simultaneously.

This overlap between proto and faux-abstraction explains why it is not always clear how to characterise certain images. Take Moholy-Nagy's Radio Tower Berlin: is this proto-abstract in virtue of formal design, faux-abstract in virtue of strange point of view - or both? If the latter, it falls in the space where two overlap. Note, however, 
that such overlap is not complete. One can estrange by photographing something at an angle or speed, or from a distance, that frustrates recognition of what one is looking at, without this entailing that the result appears abstract. Conversely, one can abstract, by foregrounding a composition's formal design properties, without thereby estranging. So the two remain in principle distinct, even if some images do both.

\section{Constructed Faux Abstraction}

Constructed faux abstraction is, as the name suggests, a variant of faux abstraction. Unlike faux abstraction, which works by alienating or estranging a scene that would otherwise be easily recognizable, constructed faux-abstraction comprises works in which the photographer constructs a scene that can be photographed so as to give rise to an image that seems (but only seems) to be abstract. There are numerous examples in recent photographic art. Barbara Kasten's Studio Constructs (2007-11) depicting arrangements of glass panes, lit and framed in such a way as to make their complex play of reflections and shadows difficult to resolve, is one obvious example. Richard Caldicott's seemingly abstract images made by photographing coloured light filtered through semi-transparent Tupperware boxes (such as Untitled \#179 [2000]) another.

James Welling's work from the late 1970s and early 1980s provides a rich seam of examples: here some simple, everyday material such as aluminum foil, filopastry, gelatin or tiles is photographed in such a way as to make it hard to make out what one is seeing. Though colloquially known as Foils, Filo, Gelatin, Tiles (etc.), the works are officially Untitled, so as not to give the game away. Like faux abstraction, that one is seeing something is typically clear, as is the fact that it exhibits volumetric form, even if precisely what one is seeing remains much less so. Welling's images of 
sheets or fragments of filo-pastry, for example, could be mistaken for paper, crisp linen sheets or shards of ice; the Foils might be harshly lit lunar surfaces, ravines or dense foliage, and so on. Like faux abstraction, such images work to delay or frustrate recognition of what one is seeing, but do so by virtue of the photographer constructing the scene before the camera for that very purpose. But because they still involve the experience of perceiving objects and scenes, even if we cannot always say what, they cannot count as abstract stricto sensu.

\section{Weak Abstraction}

Weak abstraction, by contrast, records the world in such a way as to no longer give rise to a clear experience of seeing figurative content or volumentric form. Weakly abstract photographs home in on some corner of the world, an alignment of edges or surfaces that can, when isolated by the viewfinder of a camera, be photographed in such a way as to generate an abstract or quasi-abstract composition. We may not be sure that we are seeing some corner of the world, or be able to make out what it is if we do, though we always are. The art consists in the photographer's ability to find, isolate and record the alignment in question. Like faux-abstraction, weak abstraction is pervasive; once again, photography's ability to isolate and excerpt a fragment from a wider field of view seems to invite it. Like proto-abstraction, purists will see weakabstraction as a stop on the road to abstraction proper, albeit one considerably closer to the terminus.

Examples include Aaron Siskind's well known images of walls of peeling paint, ripped fly posters, and crumbling plaster surfaces (such as Chicago 30 [1949], New York 2 [1947] or Bahia 148 [date unknown]). These are routinely included in 
surveys of abstract photography, despite the fact that it is generally clear what such images depict. Bert Danckaert's Horizon series (2014-6) offers a more recent example in a similar vein: quiet, beautifully composed, photographs focusing on junctures where two or more wall surfaces or finishes in the same plane abut one another or overlap, or a wall meets a pavement, road or grass verge at ninety degrees, but framed so that this is not immediately apparent (Horizon \#019 (Guangzhou) [2014], Horizon \#017 (Lodz) [2014]).

Absent the act of framing that brings their disparate entities into dialogue, what such images show would remain mere details in an undefined, unbounded field. In the resulting images one sees planes in shallow space rather than volumetric forms, even if those planes consist of real objects. That one recognizes worldly objects such as walls and other planar surfaces photographed parallel to the picture plane, rather than just planes of colour, shapes or lines is what makes such images weakly abstract. It also shows that recognizing three-dimensional objects need not involve perception of volumetric form. ${ }^{27}$

\section{Strong Abstraction}

Like weak abstraction, strong abstraction involves straight recording of the world. Unlike weak abstraction, it records the world in such a way as to no longer give rise to an experience, even an ambiguous or liminal one, of seeing everyday objects. The difference between weak and strong abstraction can be as minimal as how an image is

\footnotetext{
${ }^{27}$ The same is true of photograms that allow viewers to recognize everyday objects in their surfaces by means of their silhouettes, while eliciting perception of neither volumetric form nor the three-dimensional space such objects might inhabit.
} 
cropped. It is possible to take a weakly abstract work and render it strongly abstract simply by cropping away those parts of the image, such as wall edges, that enable us to recognize objects in its surface.

This will naturally give rise to the worry that weak and strong abstraction cannot be kept apart on principled grounds. A more pressing worry, however, may be that weak abstraction collapses back into proto-abstraction. For it would seem that in so far as one can make out either volumetric form or everyday objects in an image, it will count, indeterminately, as proto- and/or weakly abstract and, in so far as one cannot, it will count as strongly abstract. But this would be too quick: the difference between proto and weak abstraction is that between recognizing everyday objects exhibiting volumetric form and being able to make out everyday objects, such as wall surfaces or edges, even in the absence of such form.

With strong abstraction it may seem that we have finally reached the terminus. But note that whether or not strongly abstract works count as "abstraction proper" will depend in part on prior methodological commitments. If one's theory pivots on what a suitable viewer perceives in an image — in this case a non-volumetric formal arraysuch works will count as abstraction proper. But if one's theory pivots, not on what such a viewer should experience, but on whether or not an image does in fact record the world, even strongly abstract photographs will count as fully representationalirrespective of whether the viewer recognizes this.

Orthodox and New theorists are likely to differ with respect to such cases. Orthodox theorists will be obliged to take the latter route on pain of refusing, in the face of all evidence to the contrary, that strongly abstract works count as photographs stricto sensu. New theorists, by contrast, need not. Taking the latter route is the only 
option open to Orthodox theorists because such images do in fact record the world, even if they do so in such a way that we are unable to say what they depict. Because New theorists are not wedded to a background theory of photography as a recording medium, they will feel no pressure to withhold the epithet "abstraction" from such cases - irrespective of whether or not they straightforwardly record the world.

\section{Constructed Abstraction}

By contrast to both weak and strong abstraction, constructed abstraction involves the construction of an image from scratch: no straight recording of the world, if that is understood to be of a prior, camera independent reality, is involved. And, by contrast to the constructed variant of faux abstraction, no construction of a scene is involved either; instead it is the image itself that is now constructed from the ground up. Such images nonetheless count as photographs for New theorists because they implicate a photographic event in their causal history. Orthodox theorists, by contrast, will have to refuse to so count them, given that they are neither belief-independent, nor causally and counterfactually dependent on some prior object or scene. Lopes calls such work "Lyrical Photography," noting that it cannot be photography if Orthodoxy is true. One might equally call it "Material photography," in so far as it turns its attention inwards, onto the material processes and procedures of photography itself.

Examples include works by Wolfgang Tillmans, Walead Beshty and James Welling, among others. Tillmans's Freischwimmer series comprises sumptuous abstractions punctuated by clusters of black gestural swirls often on a scale to rival mid-Century gestural abstract painting. Generated from scratch in the darkroom, and 
despite suggesting chemicals flows, these images are made through an entirely dry process that involves manipulating the projection of light onto sheets of light sensitive photographic paper with various baffles and light emitting tools, and then enlarging the results. Beshty's "multiple-sided" images are made by exposing different facets of three-dimensional constructions made out of light sensitive photographic paper, to different coloured lights in total darkness. The constructions are then unfolded and the paper developed it in the normal way. This results in images that call to mind crumpled paper, but in which the paper itself seems to be rendered directly from coloured light. ${ }^{28}$ Though they retain some passages of volumetric form, taken as a whole the works seem clearly abstract. Finally, James Welling's Fluid Dynamics series which, like Tillmans, is reminiscent of gestural abstraction but, unlike Tillmans, is made using an entirely wet process, serves to make visible a prior, semi-liquid state of the very surface one is looking at when one looks at the image. Made by prolonged soaking of chromogenic paper in water so as to mobilize the dies in the paper surface, the paper is removed from the water and exposed to light. This fixes an image of the dies' disposition across the paper's surface. One is seeing these flows when one looks at the resulting image.

\section{Concrete Abstraction}

What I call Constructed Abstraction may initially seem close to what the Gottfried Jäger calls “Concrete Photography." On Jäger's account, this foregrounds artefacts of photographic processes or events, but has no denotative content. It takes the medium,

\footnotetext{
${ }^{28}$ Work titles (e.g. Six-Sided Picture (RGBCMY), January $11^{\text {th }} 2007$, Valencia, California,
} Fujicolor Crystal Archive [2007]) document the process of construction, colours projected (here: red, green, blue, cyan, magenta, yellow), paper used, place and date of creation. 
processes, materials and mechanisms of photography as both the means and end. So understood, Concrete Photography is a late flowering of modernism in photography. ${ }^{29}$

But not only does Concrete Photography, so understood, not exhaust the domain of abstract photography, it cannot be straightforwardly identified with abstraction more generally. Abstraction in art is typically eliminative or reductive: it removes features deemed inessential to something's continued existence as an entity of a given kind. Piet Mondrian's transformation from landscape painter to abstract painter through a process of reduction, simplification and gradual elimination of the motif is a classic example. Mondrian dispensed with the depiction of everyday objects and volumetric form, but did not thereby dispense with painting, thereby demonstrating that neither could be essential to painting. Concrete Art and Constructive Abstraction, by contrast, are typically additive: they generate an image from scratch rather than arriving at it by a process of elimination.

This is one reason Constructive Abstraction cannot be identified with Strong Abstraction: where the former constructs an image from scratch, the latter generates its images by framing pre-existing scenes in such a way as to remove any depictive cues. But a more substantive reason is that it is in principle possible to construct an image from scratch in such a way as to give rise to an experience of non-veridically seeing volumetric form. Some of the Beshtys and Tillmans do just this. Anything that gives rise to an experience of non-veridically perceiving volumetric form in this way fails the test of strong abstraction, despite being entirely constructed. This shows that

\footnotetext{
${ }^{29}$ Concrete Photography, as Jäger presents it, is the point at which Concrete Art, as defined in Theo van Doesburg's "Manifesto of Concrete Art" (1930), and Abstract Photography overlap. See "Concrete Photography," in Jäger (et al) Concrete Photography/Konkrete Fotografie, also available here: http://www.gottfried-jaeger.de/articles\%23categoryArticles?id=97.
} 
constructed and strong abstraction are distinct; though what is constructed is often also strong, it need not be.

These points of convergence between Constructed abstraction and Concrete Photography should not, however, be allowed to obscure their differences. Besides the much less programmatic nature of Constructed abstraction, on the typology I have developed, there is no pressure to endorse Jäger's normative claims for the kinds of photography he both practices and champions, to the effect that: i) such practices are the only pure form of photography (in some honorific sense of "pure") or ii) simply in virtue of taking photography's means and processes as its focus, such photography rules out subject matter or association. One of the goals of my typology is to show that what is often generically typed as "abstract photography" is a complex, multifaceted phenomenon that comes in many forms. Holding up any one such form as its telos is indefensibly reductive. And even if, contrary to fact, all works of Constructed Abstraction or Concrete Photography did renounce subject matter, this would still not suffice to show that they have no external content or referent. At the very least, such works index actions - indeed, often complex iterated processes - suggesting they may take a certain kind of performance as their subject matter. All the works by Beshty, Tillmans and Welling discussed thematize the labour of their own making and thereby comment on the, generally underplayed, labour of photography itself.

So far as abstraction in photography goes, New Theory implies not only that it is possible, but that it comes in various strands or strengths that warrant the term on various grounds, sometimes to do with differences in how images appear, other times to do with how they are made. No one such strand can be non-normatively privileged, and critical or participant preferences make a poor foundation for theory building. But 
all such photography explores the space of photographic possibility, a space that turns out to be far more capacious than Orthodoxy ever imagined. ${ }^{30}$

WORD COUNT: 7915 including footnotes, excluding abstract.

${ }^{30}$ Acknowledgements. 